\title{
MicroRNA-125b Affects Vascular Smooth Muscle Cell Function by Targeting Serum Response Factor
}

\author{
Zhibo Chen ${ }^{\mathrm{a}, \mathrm{c}}$ Mian Wang ${ }^{\mathrm{a}}$ Kai Huang ${ }^{\mathrm{c}}$ Qiong He $\mathrm{He}^{\mathrm{b}}$ Honghoo Lic \\ Guangqi Changa
}

aDivision of Vascular Surgery, Guangdong Engineering Laboratory for Diagnosis and Treatment of Vascular Disease, 'Division of Pathology, The First Affiliated Hospital, Sun Yat-sen University, Guangzhou, 'Department of Vascular and Thyroid Surgery, Sun Yat-sen Memorial Hospital, Sun Yat-sen University, Guangzhou, China

\section{Key Words}

Mir-125b • Arteriosclerosis obliterans • Smooth muscle cell • Serum response factor

\begin{abstract}
Background/Aims: Increasing evidence links microRNAs to the pathogenesis of peripheral vascular disease. We recently found microRNA-125b (miR-125b) to be one of the most significantly down-regulated microRNAs in human arteries with arteriosclerosis obliterans (ASO) of the lower extremities. However, its function in the process of ASO remains unclear. This study aimed to investigate the expression, regulatory mechanisms, and functions of miR$125 \mathrm{~b}$ in the process of ASO. Methods: Using the tissue explants adherent method, vascular smooth muscle cells (VSMCs) were prepared for this study. A rat carotid artery balloon injury model was constructed to simulate the development of vascular neointima, and a lentiviral transduction system was used to overexpress serum response factor (SRF) or miR-125b. Quantitative real-time PCR (qRT-PCR) was used to detect the expression levels of miR-125b and SRF mRNA. Western blotting was performed to determine the expression levels of SRF and Ki67. In situ hybridization analysis was used to analyze the location and expression levels of miR-125b. CCK-8 and EdU assays were used to assess cell proliferation, and transwell and wound closure assays were performed to measure cell migration. Flow cytometry was used to evaluate cell apoptosis, and a dual-luciferase reporter assay was conducted to examine the effects of miR-125b on SRF. Immunohistochemistry and immunofluorescence analyses were performed to analyze the location and expression levels of SRF and Ki67. Results: miR125b expression was decreased in ASO arteries and platelet-derived growth factor (PDGF)BB-stimulated VSMCs. miR-125b suppressed VSMC proliferation and migration but promoted VSMC apoptosis. SRF was determined to be a direct target of miR-125b. Exogenous miR-125b expression modulated SRF expression and inhibited vascular neointimal formation in ballooninjured rat carotid arteries. Conclusions: These findings demonstrate a specific role of the miR-125b/SRF pathway in regulating VSMC function and suggest that modulating miR-125b levels might be a novel approach for treating ASO.

Z. Chen and M. Wang contributed equally to this work.




\section{Introduction}

Arteriosclerosis obliterans (ASO) of the lower limbs is a common disease, inflicting a $17 \%$ morbidity rate in people aged 55 to 75 years, resulting in lower limb ischemia and even amputation. Previous research indicated that nearly $20 \%$ of people greater than 65 years of age suffer from limb arterial diseases, and ASO currently ranks as the highest incidence rate [1]. ASO leads to limb physical disabilities in thousands of elderly patients each year and is a serious threat to their health. Furthermore, with changing lifestyles, ASO increasingly occurs among younger age groups, and these trends bring heavy burdens to the families of patients and to the government. Because the effects of current drug treatments are not satisfactory [2], vascular interventional therapies, such as balloon angioplasty and stent angioplasty, have become the main therapeutic option [3]. Although interventional therapy brings immediate relief, the recurrence rate of narrowing reaches $30 \%-50 \%$ within 1 year, and nearly $12 \%$ of severe lower limb ischemia necrosis cases result in amputation [4], bringing enormous sadness to the patients and their families.

Vascular smooth muscle cells (VSMCs) are the main cells comprising the medial artery layer, which is involved in most vascular diseases. VSMC phenotypic changes, resulting in excessive proliferation and migration, are well known to be the main factors leading to ASO onset and the main cause of restenosis after interventional therapy [5]. However, how VSMCs affect the ASO process via phenotypic changes and their internal control mechanism has not been fully elucidated.

MicroRNAs are a family of highly conserved, small noncoding RNAs that can exert posttranscriptional repression functions in target gene proteins through the direct degradation or inhibition of target mRNAs involved in diverse cell functions [6-8]. Regarding arterial occlusive diseases, microRNAs regulate the functions of arterial smooth muscle cells, endothelial cells and macrophages, consequently affecting the onset and progression of ASO [9-11]. Previous studies have verified that the microRNAs miR-21, miR-143 and miR-221 are involved in the onset of occlusive vascular disease [12-14].

To study relationships between microRNAs and ASO, we collected normal femoral arteries and ASO arteries for microRNA chip screening, revealing that the expression levels of microRNAs associated with ASO were abnormal. Among these microRNAs, the aberrant expression of miR-21 and miR-1298 was verified by RT-qPCR. Using the chip screening result as a cue, miR-21 was verified to be up-regulated by HIF-1. In addition, miR-21 has been shown to regulate the proliferation and migration of VSMCs, consequently impacting the onset and progression of ASO via targeting TPM1 [12]. Furthermore, miR-1298 deficiency was related to its DNA upstream of the CpG hypermethylation site in ASO, and miR-1298 down-regulation was shown to serve a modulatory role in vascular neointimal growth and function by regulating the proliferation and migration of VSMCs via directly targeting Connexin 43[15].

In follow-up experiments in animals, microRNAs were differentially expressed in various stages of atherosclerosis (e.g., the down-regulation of miR-125b) [16]. The abnormally expressed microRNAs identified in this study are closely associated with the pathogenesis of atherosclerosis. Based on its aberrant expression at various stages of atherosclerosis, miR-133a has been recognized to regulate the functions of artery smooth muscle cells by targeting RhoA and is involved in the pathogenesis of arterial sclerosis occlusion, a kind of atherosclerosis of the lower extremities [17].

We also found miR-125b to be down-regulated in ASO arterial specimens and experimental ApoE $\mathrm{E}^{-/}$mice during a previous microRNA chip screening experiment. Furthermore, miR-125b is also down-regulated in many kinds of tumor cells, including hepatocellular carcinoma [18], breast carcinoma [19], oophoroma [20], urinary bladder carcinoma [21] and leucocythemia [22]. When miR-125b expression is up-regulated, the proliferation and invasive abilities of these cancer cells are suppressed, inducing cellular apoptosis. The disease characteristics of ASO are similar to those of tumors, and they share some common molecular mechanisms, such as aberrant cell proliferation and migration [23]. 


\section{Cellular Physiology Cell Physiol Biochem 2018;46:1566-1580 \begin{tabular}{l|l} 
and Biochemistry Published & $\begin{array}{l}\text { DOI: 10.1159/000489203 } \\
\text { a } 2018 \text { The Author(s). Published by S. Karger AG, Basel } \\
\text { www.karger.com/cpb }\end{array}$
\end{tabular} \\ Chen et al.: Effects of MiR-125b via SRF on VSMCs}

Evidence indicates that the down-regulation of miR-125b is a potential factor underlying the excessive proliferation and migration of VSMCs in ASO.

Because the function of miR-125b in ASO has not been reported, we sought to clarify the functions and molecular mechanisms of miR-125b in ASO using a series of arterial specimens, in vitro VSMCs, and animal experiments. We expect these studies to provide novel means for the diagnosis or future clinical therapeutic applications of ASO.

In this study, miR-125b was expressed mainly in arterial specimen medium, as its expression was low in neointimal ASO formation and VSMCs stimulated with platelet-derived growth factor-BB (PDGF-BB) cultured in vitro. Up-regulation of miR-125b suppressed the proliferation and migration of proliferative VSMCs and promoted cell apoptosis, and miR$125 \mathrm{~b}$ lentivirus suppressed neointimal formation in a rat carotid artery balloon injury model via targeting serum response factor (SRF).

\section{Materials and Methods}

\section{Sample acquisition and cell culture}

ASO artery samples were obtained from 16 patients with severe ASO who underwent lower limb amputation, and normal lower limb artery samples were acquired from 8 donors without ASO. Consent was obtained from either the donors or their family members. This study was approved by the Research Ethics Committee of the First Affiliated Hospital of Sun Yat-sen University (Authorization No.201502) and conformed to the Declaration of Helsinki. All samples were snap-frozen in liquid nitrogen immediately following the arteriotomy until RNA was extracted. Some of the samples were fixed with $4 \%$ paraformaldehyde and embedded in wax for further analyses. Detailed information regarding the patients and donors is provided in Table 1.

Primary human VSMCs were obtained from normal lower limb arteries using the tissue explants adherent method. VSMCs were cultured in Dulbecco's Modified Eagle's Medium (DMEM) (Invitrogen, Thermo Fisher Scientific, Inc., Waltham, MA, USA) supplemented with $10 \%$ fetal bovine serum (FBS, Invitrogen) and $100 \mu \mathrm{g} / \mathrm{ml}$ penicillin/streptomycin (Invitrogen) at $37^{\circ} \mathrm{C}$ in a humidified incubator at $5 \% \mathrm{CO}_{2}$.

\section{RNA interference}

miR-125b mimics (60 nmol/L) (RiboBio, Co., Ltd. Guangzhou, China) were used for imitation, and a miR-125b inhibitor ( $60 \mathrm{nmol} / \mathrm{L}$ ) (RiboBio) was used to deplete endogenous miR-125b. VSMCs were seeded into culture wells $24 \mathrm{~h}$ before transfection and transfected with the Lipofectamine ${ }^{\circledR}$ RNAiMAX (Invitrogen) transfection reagent according to the manufacturer's instructions. Transfection complexes were prepared and mixed either with the miR-125b mimics or the miR$125 \mathrm{~b}$ inhibitor in parallel with their respective control oligos (RiboBio, $60 \mathrm{nmol} / \mathrm{L}$ ). The transfection medium was replaced with regular cell culture medium $12 \mathrm{~h}$ after transfection. Sequences of the miR-125b mimics and the miR$125 \mathrm{~b}$ inhibitor are shown in Table 2.

Quantitative reverse
transcription PCR (qRT-
PCR)
VSMCs $\left(1 \times 10^{4}\right.$ cells per
well) were seeded in 6-well plates $24 \mathrm{~h}$ before transfection.

Table 1. Patients and donors Information

\begin{tabular}{lccccccc}
\hline NO. & Gender & Age & Diagnosis & $\begin{array}{c}\text { Smoking } \\
\text { (years) }\end{array}$ & $\begin{array}{c}\text { Alcohol } \\
\text { (years) }\end{array}$ & $\begin{array}{c}\text { Hypertension } \\
\text { (years) }\end{array}$ & $\begin{array}{c}\text { T2DM/Blood } \\
\text { glucose(mM) }\end{array}$ \\
\hline 1 & M & 66 & ASO & 30 & 40 & 10 & $10 / 12.5$ \\
2 & F & 65 & ASO & - & 40 & 15 & $10 / 12$ \\
3 & M & 73 & ASO & 50 & 40 & 20 & $15 / 10.5$ \\
4 & M & 60 & ASO & - & - & 8 & $-/ \mathrm{N}$ \\
5 & M & 56 & ASO & - & 20 & - & $-/ \mathrm{N}$ \\
6 & F & 64 & ASO & - & - & 15 & $15 / 8.5$ \\
7 & M & 58 & ASO & 30 & 30 & - & $-/ 7.4$ \\
8 & M & 68 & ASO & 40 & 40 & 10 & $-/ 7.5$ \\
9 & M & 71 & ASO & 50 & 50 & 15 & $10 / 10.5$ \\
10 & M & 55 & ASO & 30 & 30 & - & $-/ 7.8$ \\
11 & F & 62 & ASO & 20 & 20 & 10 & $10 / 9.2$ \\
12 & M & 67 & ASO & - & 40 & 10 & $10 / 9.5$ \\
13 & M & 63 & ASO & 40 & 40 & 5 & $-/ \mathrm{N}$ \\
14 & M & 58 & ASO & 35 & 40 & 10 & $-/ \mathrm{N}$ \\
15 & F & 56 & ASO & - & 30 & - & $-/ \mathrm{N}$ \\
16 & F & 66 & ASO & - & 30 & 15 & $15 / 11.5$ \\
17 & M & 36 & Normal & - & - & - & - \\
18 & F & 42 & Normal & - & - & - & - \\
19 & M & 40 & Normal & - & - & - & - \\
20 & M & 51 & Normal & - & - & - & - \\
21 & M & 32 & Normal & - & - & - & - \\
22 & F & 45 & Normal & - & - & - & - \\
23 & F & 39 & Normal & - & - & - & - \\
24 & F & 54 & Normal & - & - & - & - \\
\hline
\end{tabular}




\section{Cellular Physiology Cell Physiol Biochem 2018;46:1566-1580

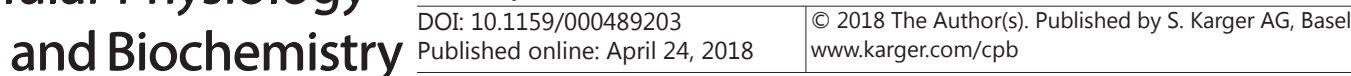 \\ Chen et al.: Effects of MiR-125b via SRF on VSMCs}

After RNA interference was performed, the cells were cultured for an additional 48 $\mathrm{h}$ using normal medium. The cells were washed twice with PBS, and total RNA was isolated using TRIzol (Invitrogen) according to the manufacturer's instructions. Total RNA was reverse transcribed using a miRNA RT kit (Takara Biotechnology Co., Ltd., Beijing, China) at $37^{\circ} \mathrm{C}$ for $60 \mathrm{~min}$ and $85^{\circ} \mathrm{C}$ for $5 \mathrm{sec}$ or an mRNA RT kit (Takara) at $37^{\circ} \mathrm{C}$ for $15 \mathrm{~min}$ and $85^{\circ} \mathrm{C}$ for $5 \mathrm{sec}$. cDNA was used as an amplification template with SYBR PrimeScript miRNA or an mRNA Real-Time PCR kit (Takara) for qPCR analysis according to the manufacturer's protocol. cDNA was amplified by real-time PCR and quantified using SYBR Green (Takara) on a CFX96 thermocycler (Bio-Rad, Hercules, California, USA) according to the manufacturer's instructions. For miR-125b amplification, the PCR conditions were as follows: $95^{\circ} \mathrm{C}$ for $10 \mathrm{sec} ; 39$ cycles of $95^{\circ} \mathrm{C}$ for $5 \mathrm{sec}$ and $60^{\circ} \mathrm{C}$

Table 3. Sequences of the PCR primers

\begin{tabular}{lrr}
\hline Name & & Sequence \\
\hline miR-125b & & 5'-TCCCTGAGACCCTAACTTGTGA -3' \\
U6 & & 5'-ACGCAAATTCGTGAAGCGTT -3' \\
SRF & Forward & 5'-CGCTACACGACCTTCAGCAAGA -3' \\
SRF & Reverse & 5'-CAGCAACAGCACCTGTGTCC -3' \\
GAPDH & Forward & 5'-GCACCGTCAAGGCTGAGAAC-3' \\
GAPDH & Forward & 5'-TGGTGAAGACGCCAGTGGA-3' \\
\hline
\end{tabular}

Table 4. Sequence of the probe for the in situ hybridization

\begin{tabular}{lc}
\hline Name & Sequence \\
\hline miR-125b Probe & 5'-TCACAAGTTAGGGTCTCAGGGA-3' \\
\hline
\end{tabular}
for $20 \mathrm{sec}$, followed by a third step at $95^{\circ} \mathrm{C}$ for $15 \mathrm{sec}$ and $65^{\circ} \mathrm{C}$ for $10 \mathrm{sec}$; and a final hold at $95^{\circ} \mathrm{C}$. For SRF mRNA amplification, the PCR conditions were as follows: $95^{\circ} \mathrm{C}$ for $30 \mathrm{sec} ; 39$ cycles of $95^{\circ} \mathrm{C}$ for $3 \mathrm{sec}$ and $60^{\circ} \mathrm{C}$ for $30 \mathrm{sec}$, followed by a third step at $95^{\circ} \mathrm{C}$ for $15 \mathrm{sec}$ and $60^{\circ} \mathrm{C}$ for $10 \mathrm{sec}$; and a final hold at $95^{\circ} \mathrm{C}$. Relative SRF and miR-125b expression levels were calculated according to the comparative cycling threshold (CT) method using the expression of the housekeeping genes U6 small nuclear RNA and GAPDH as controls, respectively. All primers were synthesized by Takara Biotechnology Co. Ltd, and the primer sequences are shown in Table 3.

\section{In situ hybridization assay}

In situ hybridization (FISH) was performed using a 5' DIG-labeled LNA probe (Exiqon, Co., Ltd., Vedbaek, Denmark) for miR-125b (sequence shown in Table 4) and miRCURY LNA ${ }^{\mathrm{TM}}$ Detection Control Probes (Exiqon) on 5- $\mu$ m-thick sections fixed in $4 \%$ paraformaldehyde and embedded in paraffin. Briefly, the slides were deparaffinized with xylene and rehydrated in a graded ethanol series $(2 \times 100 \%, 95 \% 75 \%$, $60 \%$, and 50\%). After washing with PBS, the slides were digested with $10 \mu \mathrm{g} / \mathrm{mL}$ proteinase $\mathrm{K}$ (Invitrogen) for $5 \mathrm{~min}$ at $37^{\circ} \mathrm{C}$, rinsed in $0.2 \%$ glycine/PBS ( $5 \mathrm{~min}, 3$ times), post-fixed in $4 \%$ paraformaldehyde for $10 \mathrm{~min}$, and acetylated in acetic anhydride/triethanolamine at room temperature for $10 \mathrm{~min}$ before being washed in PBS. Then, the slides were prehybridized in hybridization buffer $(50 \times$ Denhardts's solution; $60 \%$ formamide, $300 \mu \mathrm{g} / \mathrm{ml}$ transfer RNA, 20× saline sodium citrate (SSC) buffer and $1 \mathrm{M}$ dithiothreitol (Invitrogen)) at $49.5^{\circ} \mathrm{C}$ for $30 \mathrm{~min}$ and hybridized with the probes $(1: 1000)$ at $49.5^{\circ} \mathrm{C}$ for $12 \mathrm{~h}$. The slides were washed twice in $2 \times \mathrm{SSC}$ at $49.5^{\circ} \mathrm{C}$ for $5 \mathrm{~min}$, and the sections were blocked for $30 \mathrm{~min}$ at $37^{\circ} \mathrm{C}$ using $2 \%$ bovine serum albumin (BSA) (Sigma-Aldrich, Darmstadt, Germany). Subsequently, the anti-digoxigenin antibody (Roche Diagnostics, Basel, Switzerland) was added at a dilution of 1:400 and incubated at $37^{\circ} \mathrm{C}$ for $2 \mathrm{~h}$. After being washed 3 times with PBS, the slides were incubated with tyramide signal amplification buffer (TSA, 1:50; Focofish, Inc, Guangzhou, China) at room temperature for $10 \mathrm{~min}$ in the dark and then washed 3 more times with PBS. Immunofluorescence was performed to determine SM- $\alpha$-actin or SRF localization and expression using anti-SM- $\alpha$-actin (1:1000, Abcam, Cambridge, UK) and anti-SRF (1:800, Cell Signaling Technology, Boston, MA, USA ) at $37^{\circ} \mathrm{C}$ for another $2 \mathrm{~h}$. Finally, the slides were covered with a cover slip, photographed and analyzed using ImagePro Plus 6.0 (Media Cybernetics Inc., Rockville, MD, USA). The in situ hybridization probe sequences are shown in Table 4.

\section{Immunohistochemistry (IHC)/Immunofluorescence (IF)}

Immunohistochemistry and immunofluorescence were performed on 5 - $\mu$ m-thick $4 \%$ paraformaldehyde-fixed, paraffin-embedded sections. The sections were heated at $60^{\circ} \mathrm{C}$ for $2 \mathrm{~h}$, washed 2 times in xylene for $15 \mathrm{~min}$ and hydrated in an ethanol series (100\%, 95\% 75\%, 60\%, and 50\%) for 5 min each. Then, the sections were washed with PBS 2 times, and heat-mediated antigen retrieval was performed 
Chen et al.: Effects of MiR-125b via SRF on VSMCs

with sodium citrate buffer. The sections were then incubated in $3 \% \mathrm{H}_{2} \mathrm{O}_{2}$ for 20 min and washed 3 times with PBS. Blocking was performed with 10\% BSA (Sigma-Aldrich) for $30 \mathrm{~min}$ at room temperature in a humidified chamber, and the slides were washed with PBS 2 times. Then, the sections were incubated with anti-SRF (1:800, CST), anti-Ki67 (1:1000, Abcam), or anti-SM- $\alpha$-actin $(1: 1000, \mathrm{Abcam})$ at $4^{\circ} \mathrm{C}$ overnight. Subsequently, the slides were washed 3 times with PBS and treated with a rabbit/mouse secondary immunohistochemistry antibody (ZSGB-Bio, Beijing, China) according to the manufacturer's instructions for IHC. A second immunofluorescence antibody (Alexa Fluor, Invitrogen) was used for IF. Integrated optical density (IOD) values, which represent the staining intensity, were calculated for the acquired images using ImagePro Plus 6.0 (Media Cybernetics).

\section{Western blot analysis}

VSMCs $\left(1 \times 10^{4}\right.$ cells per well) were seeded in 6 -well plates $24 \mathrm{~h}$ before transfection. After RNA interference was performed, the cells were cultured for an additional $72 \mathrm{~h}$ using normal medium. The cells were washed 3 times with PBS and lysed in RIPA lysis buffer (CST) supplemented with protease inhibitors (Roche Diagnostics). Total protein concentrations were determined using a NanoDrop 2000 microvolume spectrophotometer (Thermo Scientific). Total protein lysates were separated by $10 \%$ sodium dodecyl sulfate-polyacrylamide gel electrophoresis (SDS-PAGE) and transferred to polyvinylidene fluoride (PVDF) membranes (Millipore, Billerica, MA, USA). The membranes were blocked with 5\% non-fat dry milk in TBS buffer at $37^{\circ} \mathrm{C}$ for $2 \mathrm{~h}$ and then incubated with the anti-human SRF (CST, 1:1000 dilution) and $\beta$-tubulin (CST, 1:1000) primary antibodies overnight at $4^{\circ} \mathrm{C}$. The membranes were incubated with a secondary rabbit antibody at $37^{\circ} \mathrm{C}$ for $2 \mathrm{~h}$. Relative protein expression levels were normalized to those of $\beta$-tubulin. The signals were detected using Luminol Reagent (Thermo Scientific) and imaged with a GE ImageQuant LAS 4000 phosphorimager (GE Healthcare Life Sciences, Fairfield, IA, USA) with ImageJ software (https:// imagej.nih.gov/ij/).

\section{Cell proliferation}

VSMCs $\left(2 \times 10^{3}\right.$ cells per well) were seeded in 96 -well plates in triplicate $12 \mathrm{~h}$ before transfection. After RNA interference was performed, the cells were cultured for $24 \mathrm{~h}$ in normal medium and $24 \mathrm{~h}$ in serumfree DMEM. In addition to the control group, $20 \mathrm{ng} / \mathrm{ml}$ PDGF-BB was added to each well for $24 \mathrm{~h}$. For the cell counting kit-8 (CCK-8) assay, $10 \mu \mathrm{l}$ of CCK-8 solution (Dojindo, Tokyo, Japan) was added to each well for $1 \mathrm{~h}$, and the absorbance values were then measured at $450 \mathrm{~nm}$ using a spectrophotometer. For the EdU assay, cells were incubated with $50 \mu \mathrm{M}$ EdU (Ribobio) for $2 \mathrm{~h}$ and then fixed with $4 \%$ paraformaldehyde for $15 \mathrm{~min}$. The cells were subsequently treated with $100 \mu \mathrm{l}$ of Apollo reaction cocktail at room temperature for $30 \mathrm{~min}$, followed by $50 \mu \mathrm{l}$ of $1 \%$ Hoechst 33342 (Ribobio) at room temperature for $30 \mathrm{~min}$ for nuclei staining. Finally, an inverted fluorescence microscope (Axio Observer Z1, ZEISS, Oberkochen, Germany) was used for visualization. Ten random microscopic fields in each well were photographed and imaged, and the number of Apollo-positive nuclei was divided by the total number of nuclei stained with Hoechst 33342. Fluorescence images were analyzed using ImagePro ${ }^{\circledR}$ Plus software 6.0 (Media Cybernetics).

\section{Cell migration}

Transwell and wound closure assays were used to assess cell migration. VSMCs were seeded in 6-well plates in triplicate $24 \mathrm{~h}$ before transfection. After RNA interference was performed, the cells were cultured for $24 \mathrm{~h}$ in normal medium and $24 \mathrm{~h}$ in serum-free DMEM. For the transwell assay, VSMCs were resuspended in serum-free DMEM $\left(5 \times 10^{5} \mathrm{cells} / \mathrm{ml}\right)$ after digestion, and $200 \mu \mathrm{l}$ of the mixture was added to the upper chamber of a Transwell insert (BD Falcon, Franklin Lakes, NJ, USA) in a 24-well plate. Next, $500 \mu$ l of serumfree DMEM with or without $10 \mathrm{ng} / \mathrm{ml}$ PDGF-BB was added to the lower chamber as the control. After 12 hours of incubation, cells migrated to the lower face of the chamber membrane, and cells remaining on the upper face of the membrane were removed by a cotton swab. Cells adhered to the lower face were fixed with $4 \%$ paraformaldehyde and subsequently stained with $0.1 \%$ crystal violet. After being washed three times with PBS, migrated VSMCs were imaged and counted using an inverted microscope (Axio Observer Z1, ZEISS, $20 \times$ magnification). For the wound closure assay, wounds in each well were scratched using a sterilized 200$\mu \mathrm{l}$ disposable pipette tip, and the assay was performed in triplicate. The medium was replaced with serumfree DMEM supplemented with $10 \mathrm{ng} / \mathrm{ml}$ PDGF-BB in addition to the control group. Scratch wounds were immediately visualized using an inverted microscope (Axio Observer Z1, ZEISS). The cells were cultured 
for another $24 \mathrm{~h}$ and then visualized again at the previous position. The widths of the scratch wounds were measured using ImagePro ${ }^{\circledR}$ Plus software 6.0 (Media Cybernetics).

\section{Cell apoptosis}

Flow cytometry analysis was used to evaluate cell apoptosis. VSMCs $\left(1 \times 10^{5}\right.$ cells per dish $)$ were seeded in culture dishes $24 \mathrm{~h}$ before oligo transfection, and normal culture medium was replaced with serum-free DMEM for another $48 \mathrm{~h}$. Cells were washed twice with PBS, digested with EDTA-free trypsin, harvested, and washed three more times with PBS. The cells were double-stained with FITC-conjugated V and propidium iodide (PI) from the detection kit (Dojindo) according to the manufacturer's instructions. The percentages of viable cells (annexin V- and PI-negative), apoptotic cells (annexin V-positive and PI-negative) and necrotic cells (annexin V- and PI-positive) were detected using an EPICS XL-MCL ${ }^{\mathrm{TM}}$ flow cytometry system (Beckman Coulter, Fullerton, CA, USA). The results were analyzed using Kaluza 1.2 software (Beckman Coulter).

\section{3'-untranslated region (3'-UTR) luciferase assay}

Using TargetScan 7.1 (http:// www.targetscan.org/), SRF was selected as a potential miR-125b target based on the complementarity of its mRNA 3'-UTR to miR-125b. SRF mRNA 3'-UTR miR-125b binding sites were amplified by PCR and cloned into the pLUC luciferase reporter vector (Kangbio, Guangzhou, China) to construct the fluorescent reporter system. pLUC vectors containing the SRF mRNA 3'-UTR with miR-125bmutated binding site 1 (Mut1), miR-125b-mutated binding site 2 (Mut2), or miR-125b-mutated binding sites 1 and 2 (Mut1\&2) were also generated. HEK293T cells were cultured in triplicate to 70\% confluency in 96-well plates and co-transfected with the luciferase reporter vectors (either the wild-type or one of the three mutant SRF 3'-UTRs) and the miR-125b mimics or control oligo (Ribobio) $(60 \mathrm{nmol} / \mathrm{l})$ using FuGENE ${ }^{\circledR}$ HD (Roche) according to the manufacturer's instructions. After $48 \mathrm{~h}$, the cells were lysed, and luciferase activity was measured using the Dual-Glo ${ }^{\mathrm{TM}}$ Luciferase Assay kit (Promega, Madison, WI, USA) according to the manufacturer's instructions. Sequences of the 3'-UTR primers used for the luciferase assay are shown in Table 5 and Table 6.

\section{Lentiviral transduction}

According to the manufacturer's instructions, HEK293 cells were re-cotransfected with $2.5 \mu \mathrm{g}$ of the Lenti-Pac HIV plasmid (GeneCopoeia) and SRF cDNA (GeneCopoeia) to produce lentiviral particles. The particles were collected $48 \mathrm{~h}$ later, and serum-free medium containing $20 \mu \mathrm{g} / \mathrm{mL}$ polybrene (Sigma) was mixed with the filtrate (containing virus), incubated overnight with the cultured cells, and then replaced with growth medium for an additional $24 \mathrm{~h}$. The cells were selected using $10 \mu \mathrm{g} / \mathrm{mL}$ puromycin (Sigma) for 2 days according to the manufacturer's instructions. The lentiviral particles were collected and stored at $-80^{\circ} \mathrm{C}$.

\section{Rat carotid artery balloon injury model}

The carotid artery balloon injury and lentivirus-mediated gene transfer were performed in SPF male Sprague Dawley rats (Silaike Jingda, Hunan, China) (250 to $300 \mathrm{~g}$ ) as described previously [24]. Pentobarbital sodium $(40 \mathrm{mg} / \mathrm{kg}$ ) was used to narcotize the rats. The drugs were added until their pedal pinch reflexes were completely inhibited and they had no response to a needle stimulus. Anaesthetized rats were placed on a warming plate to maintain their body temperature at $37^{\circ} \mathrm{C}$ to minimize pain caused by the procedure. Using a dissecting microscope, the right common carotid artery was exposed through a midline cervical incision. A $2 \mathrm{~F}$ Fogarty catheter (Edwards Lif es ciences, Irvine, CA, USA) was inserted via an arteriotomy

Table 5. Sequences of the primers used for amplifying the wild-type SRF 3'-UTR

\begin{tabular}{lc}
\hline Name & Sequence \\
\hline SRFXhol Forward: & 5'-ccgctcgagTCCGCCCGCCGCCCTG-3' \\
SRFNotI Reverse: & 5'-ataagaatgcggccgcTCTGTGCACAAAAATGATACATTTATTG-3' \\
\hline
\end{tabular}

Table 6. Sequences of the primers used for mutating the miR-125b binding sites in the SRF

\begin{tabular}{lc}
\hline Name & Sequence \\
\hline mutSRF-1Forward: & 5'-AAAGAGCCCTGGCTCTGCCCGAGTCCCGGCCAGCTGGGGAGATGGGG-3' \\
mutSRF-1Reverse: & 5'-CCCCATCTCCCCAGCTGGCCGGGACTCGGGCAGAGCCAGGGCTCTTT-3' \\
mutSRF-2Forward: & 5'-CTTGGGAGGACATGCGTGTGAGTCCCTTGAGTTGAGGTGATATTTTT-3' \\
mutSRF-2Reverse: & 5'-AAAAATATCACCTCAACTCAAGGGACTCACACGCATGTCCTCCCAAG-3' \\
mutSRF-1\&2Forward: & 5'-CTTGGGAGGACATGCGTGTGAGTCCCTTGAGTTGAGGTGATATTTTT-3' \\
mutSRF-1\&2Reverse: & 5'-AAAAATATCACCTCAACTCAAGGGACTCACACGCATGTCCTCCCAAG-3' \\
\hline
\end{tabular}




\section{Cellular Physiology Cell Physiol Biochem 2018;46:1566-1580

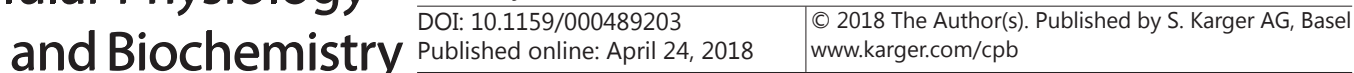 Chen et al.: Effects of MiR-125b via SRF on VSMCs}

in the external carotid artery and pushed forward to the edge of the sternum, which was very near the omohyoid muscle edge. To induce the carotid artery wall injury, the balloon was dilated with saline and pulled backwards and forwards three times while continuously rotating the catheter from the edge of the sternum to the carotid bifurcation. Following the balloon injury, a solution containing miR-125b-LV $\left(5 \times 10^{9}\right.$ $\mathrm{pfu} / \mathrm{mL})$ and $\mathrm{NC}-\mathrm{LV}\left(5 \times 10^{9} \mathrm{pfu} / \mathrm{mL}\right)$ was infused into the provisionally closed segment of the right common carotid artery by an artery clamp and held for $40 \mathrm{~min}$. The right external carotid artery was then ligated with a 6-0 silk suture, and the artery clamp was relieved so that blood flow to the right common carotid artery was recanalized. The rats were sacrificed using pentobarbital sodium (150 mg/kg) 2 weeks later for analysis of the carotid artery balloon injury model. All protocols were authorized by the Institutional Animal Care and Use Committee of the First Affiliated Hospital of Sun Yat-sen University and were in accordance with the Guide for the Care and Use of Laboratory Animals (https://doi.org/10.1093/ilar/ilw049).

\section{Statistical analyses}

Statistical analyses were conducted with Student's $t$-tests for average (mean) comparisons or one-way ANOVA for multiple comparisons to identify significant differences. Relationships between variables were determined by the Pearson correlation coefficient. $P$-values $<0.05$ were considered significant. All data were processed using GraphPad Prism 5.0 and SPSS software (version 17.0).

\section{Results}

miR-125b expression was decreased in ASO arteries and PDGF-BB-stimulated VSMCs

Our previous study revealed miR$125 \mathrm{~b}$ expression to be significantly downregulated in ASO arteries compared with that in normal arteries. In the present study, we confirmed that miR-125b expression was significantly down-regulated by $\sim 70 \%$ in ASO arteries compared with that in normal arteries using a qRT-PCR assay (Fig. 1A). To determine the distribution of miR-125b in the artery wall, three ASO arterial layers were dissected, and miR$125 \mathrm{~b}$ expression was detected using qRTPCR. As shown in Fig. 1B, miR-125b was expressed primarily in the artery media, which was mainly composed of VSMCs, rather than the intima and adventitia. To further assess the cellular distribution of miR-125b in the artery wall, we performed co-IF with the smooth muscle marker SM$\alpha$-actin. miR-125b (red) co-localized with SM- $\alpha$-actin (green) in the artery media and was remarkably down-regulated in ASO arteries (Fig. 1C). In addition, when VSMCs were stimulated with PDGF-BB (10 $\mathrm{ng} / \mathrm{ml}, 0 \sim 48 \mathrm{~h}$ ), miR-125b expression was down-regulated (Fig. 1D). These findings indicate that miR-125b is expressed mainly in VSMCs and suggest that miR-125b is down-regulated in ASO VSMCs and PDGFBB-stimulated VSMCs cultured in vitro.

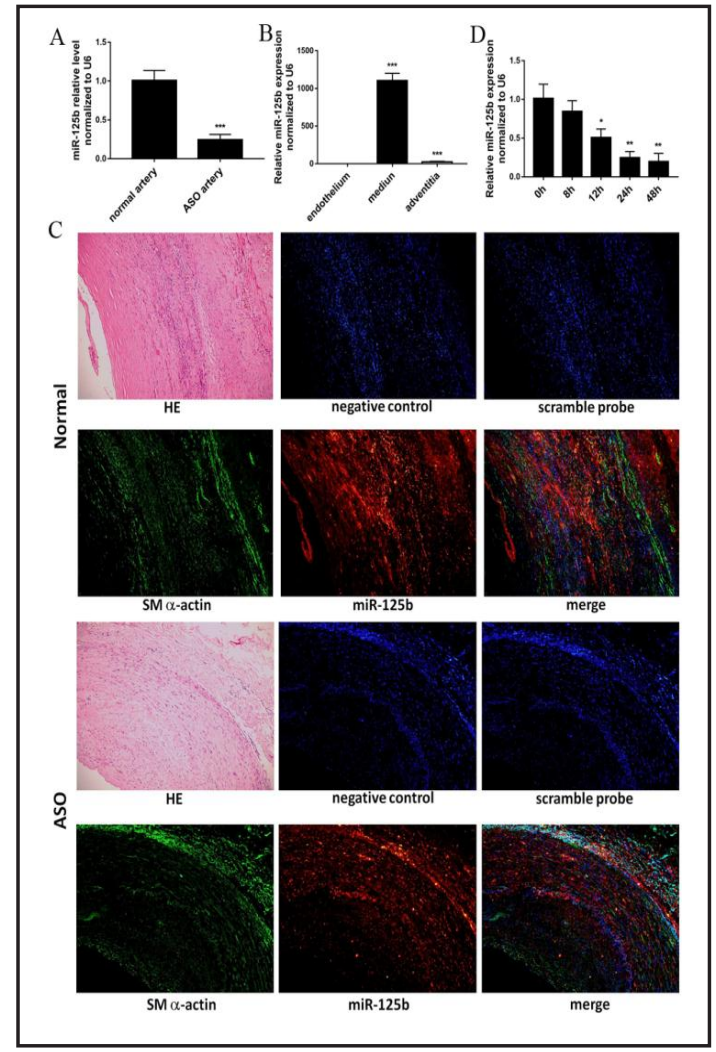

Fig. 1. Characteristics of miR-125b expression in ASO arteries. (A, C) miR-125b is expressed in ASO arteries at low levels, as determined by qRTPCR and FISH assays. ${ }^{* * *} \mathrm{p}<0.001$ compared with the normal artery group. (B) miR-125b is mainly expressed in the medium of normal arteries, as determined by qRT-PCR. ${ }^{* * *} \mathrm{p}<0.001$ compared with the endothelium group or the normal artery group. (D) miR-125b is expressed at low levels in PDGFBB-stimulated VSMCs, as determined by qRT-PCR. ${ }^{*} \mathrm{p}<0.05,{ }^{* *} \mathrm{p}<0.01$ compared with the 0 h group. 


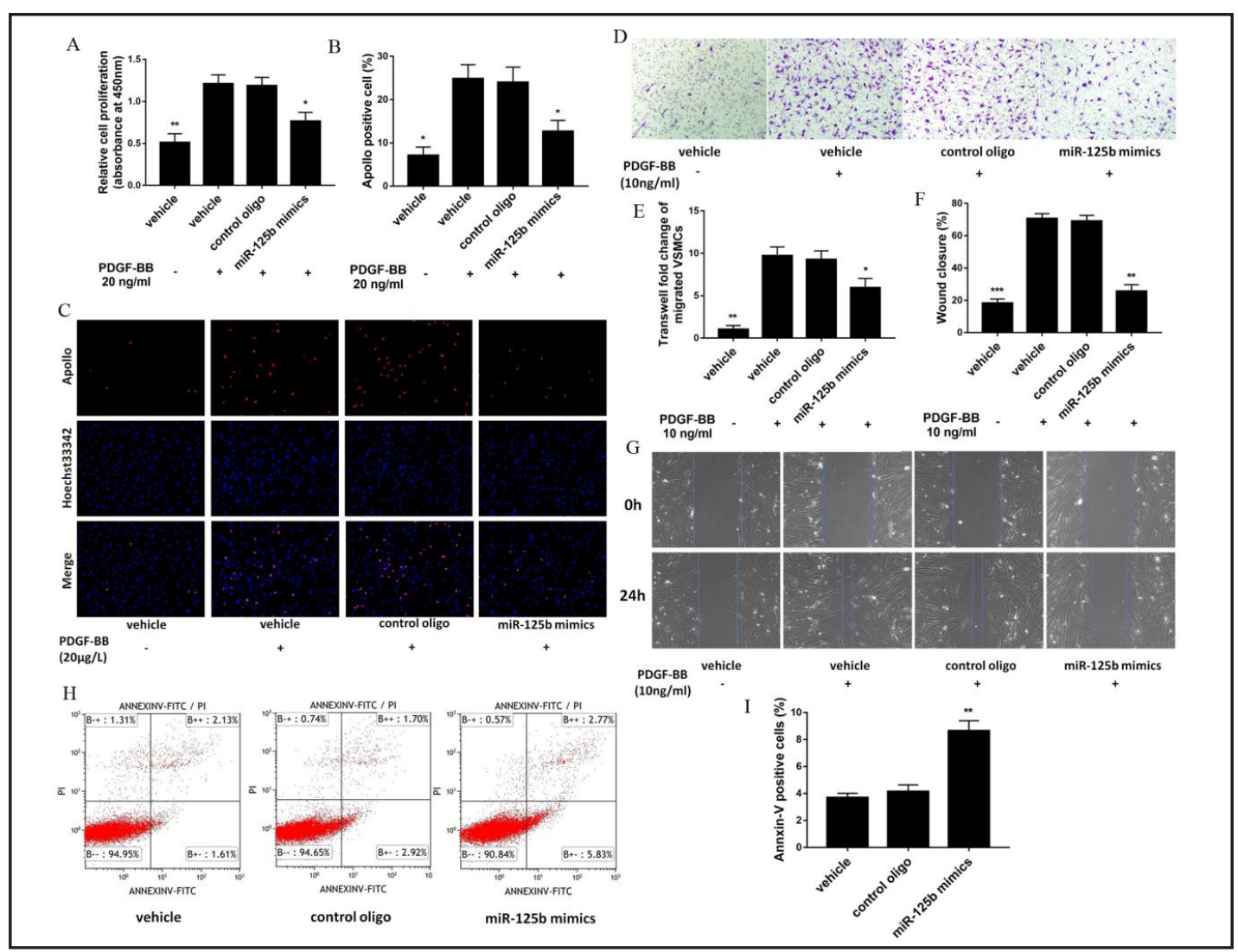

Fig. 2. Effects of miR-125b mimics on cultured VSMCs. (A-C) miR-125b mimics significantly suppressed the proliferation of VSMCs, as determined by CCK- 8 and EdU assays. ${ }^{*} p<0.05$, ${ }^{* *} p<0.01$ compared with the vehicle-treated PDGF-BB group. (D-G) miR-125b mimics significantly suppressed the migration of VSMCs, as determined by transwell and wound closure assays. ${ }^{*} \mathrm{p}<0.05,{ }^{* *} \mathrm{p}<0.01,{ }^{* * *} \mathrm{p}<0.001$ compared with the vehicle-treated PDGF-BB group. (H-I) miR-125b mimics significantly promoted the apoptosis of VSMCs, as determined by the annexin $\mathrm{V} / \mathrm{PI}$ dual-staining assay. ${ }^{* *} \mathrm{p}<0.01$ compared with the vehicle group.

miR-125b inhibited VSMC proliferation and migration but promoted VSMC apoptosis

Excessive VSMC proliferation and migration are key cellular events in the process of arteriosclerosis [25]. To explore the cellular effects of abnormal miR-125b expression in ASO, we introduced miR-125b mimics into cultured VSMCs. Fig. 2A-C shows that the proliferation of PDGF-BB-stimulated VSMCs was significantly inhibited by the miR-125b mimics, as determined by the CCK- 8 and EdU assays, and miR-125b significantly decreased the PDGF-BB-induced migration of VSMCs (Fig. 2D-G). In addition, the annexin V/PI dual staining assay showed that miR-125b markedly increased the number of apoptotic VSMCs (Fig. 2H-I). These results revealed that miR-125b might suppress VSMC proliferation and migration but promotes VSMC apoptosis in vitro.

\section{SRF is a direct target of miR-125b}

As predicted by TargetScan 7.1, SRF was selected as a potential miR-125b target based on its mRNA 3'-UTR complementarity to miR-125b. miR-125b was predicted to target two potential regions of the SRF mRNA 3'-UTR (bp 470-476 and bp 2055-2061) (Fig. 3A).

Analyzing human ASO and normal artery samples by Western blot and IHC showed that the SRF protein level in ASO arteries was significantly higher than that in normal arteries (Fig. 4A-D). In contrast, FISH analysis showed that the miR-125b level in ASO arteries was significantly lower than that in normal arteries (Fig. 1B-C). These results indicated a

\section{KARGER}


Fig. 3. $\operatorname{miR}-125 b$ exerts a regulatory function via its direct target gene SRF. (A) SRF was selected as a potential miR-125b target because of its mRNA 3'-UTR complementarity, as two complementary sites to miR$125 \mathrm{~b}$ were predicted by TargetScan online. (B-C) SRF protein levels were down-regulated by miR-125b mimics (60 nmol/L) but up-regulated by a miR-125b inhibitor $(60 \mathrm{nmol} / \mathrm{L})$, as assessed by Western blot. ${ }^{* *} \mathrm{p}<0.01$ compared with the vehicle group. (D) The SRF mRNA levels were minimally down-regulated by miR-125b mimics but slightly upregulated by the miR-125b inhibitor (60 $\mathrm{nmol} / \mathrm{L})$, as as-

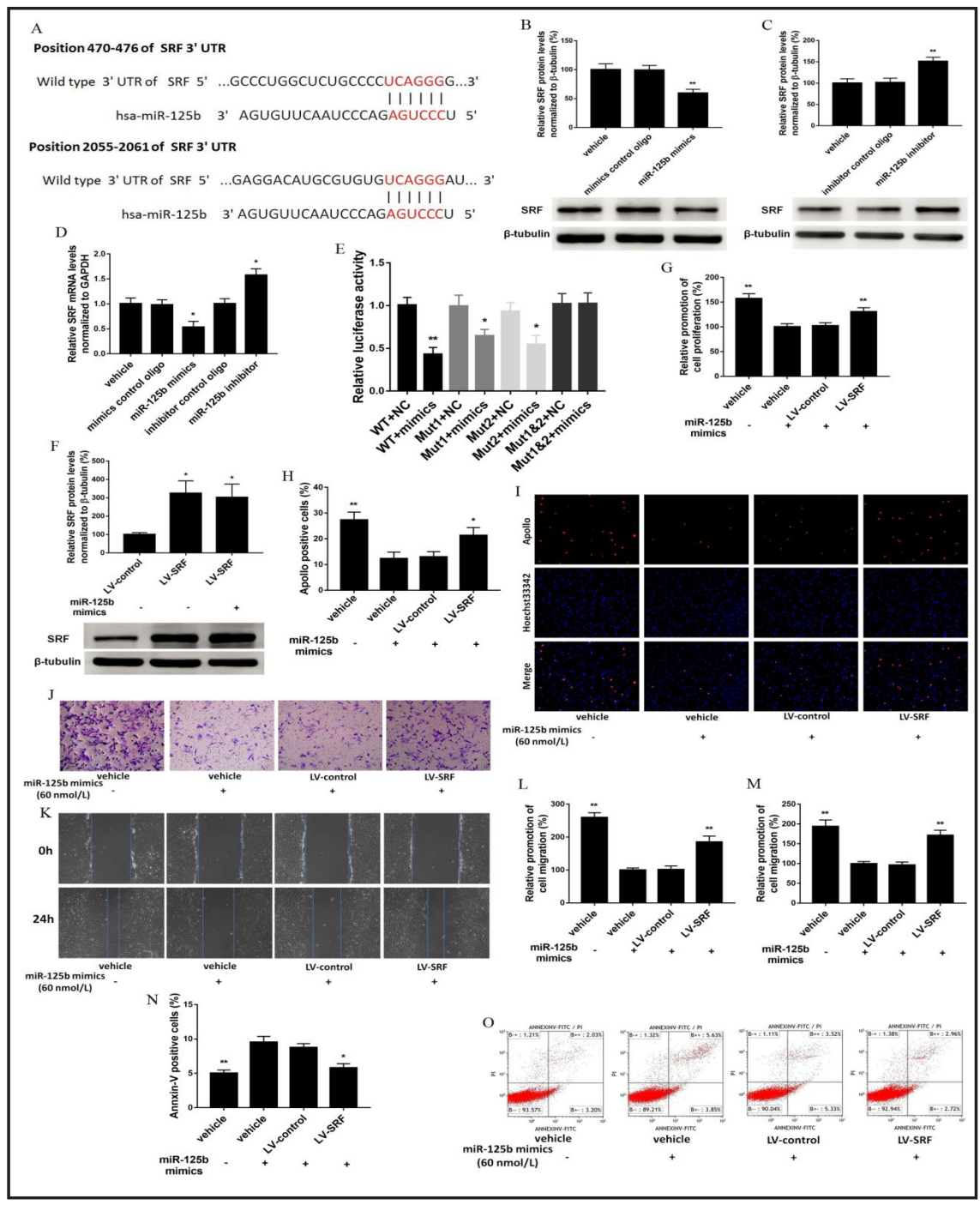
sessed by qRT-PCR.

${ }^{*} \mathrm{p}<0.05$ compared with the vehicle group. (E) Co-transfection of miR-125b mimics with the wild-type SRF 3'-UTR (WT) or either of the two SRF 3'-UTR mutants in HEK293T cells led to a marked decrease in luciferase activity, whereas co-transfection of the miR-125b mimics with the two completely mutated SRF 3'-UTRs had no effect on luciferase activity. ${ }^{*} \mathrm{p}<0.05,{ }^{* *} \mathrm{p}<0.01$ compared with the WT+NC group. (F) Overexpression of SRF in VSMCs was achieved using a lentivirus vector (LV-SRF), and LV-SRF expression could not be effectively suppressed by the miR-125b mimics, as determined by Western blot analysis. ${ }^{*} \mathrm{p}<0.05$ compared with the LV-control group. (G-I) The proliferative capacity of cultured VSMCs was partly recovered by the administration of SRF lentivirus, as determined by CCK- 8 and EdU assays. ${ }^{*} \mathrm{p}<0.05,{ }^{* *} \mathrm{p}<0.01$ compared with the vehicle-treated miR-125b mimic group. (J-M) The effect of miR-125b suppression on the migration of cultured VSMCs was partly attenuated by the administration of SRF lentivirus, as determined by transwell and wound closure assays. ${ }^{* *}$ p $<0.01$ compared with the vehicle-treated miR-125b mimic group. (N-0) The SRF lentivirus partly alleviated the promotional effects of miR-125b mimics on the apoptosis of cultured VSMCs, as shown by the annexin V/PI dual staining assay. ${ }^{*} \mathrm{p}<0.05,{ }^{* *} \mathrm{p}<0.01$ compared with the vehicletreated miR-125b mimic group.

negative correlation between SRF and miR-125b expression in vivo. Moreover, in cultured VSMCs, miR-125b mimics significantly decreased SRF protein expression, while the miR125b inhibitor moderately increased SRF protein expression (Fig. 3B and C). In addition, miR-125b slightly down-regulated the SRF mRNA level (Fig. 3D). These findings suggest that 


\section{Cellular Physiology Cell Physiol Biochem 2018:46:1566-1580

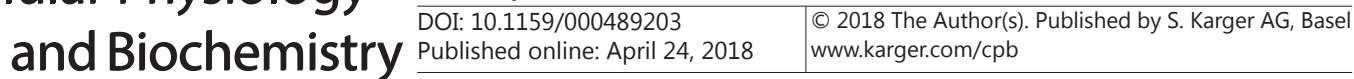 \\ Chen et al.: Effects of MiR-125b via SRF on VSMCs}

SRF might be a direct target of miR-125b.

To investigate whether miR-125b directly binds the SRF mRNA 3'-UTR and consequently regulates its expression, two putative miR-125b binding sites in the SRF mRNA 3'-UTR region were constructed in a dual-luciferase reporter vector. In the presence of the wild-type SRF mRNA 3'-UTR and either of the two SRF mRNA 3'-UTR mutants, miR-125b significantly decreased the relative luciferase activity. When the two miR-125b seed sequences in the SRF mRNA 3'-UTR were totally mutated, the inhibitory effect of miR-125b on the relative luciferase activity was abrogated. The suppressive degree of the mut2 3'-UTR position was more remarkable than that of the mut1 3'-UTR. (Fig. 3E). We hypothesized that the 2nd 3'-UTR position has a stronger ability to bind miR-125b mimics. Together, these results confirmed that SRF is a direct target of miR-125b.

Additionally, to determine whether SRF is involved in cellular effects induced by miR-125b, we overexpressed SRF in VSMCs via an SRF lentiviral vector (LV-SRF) (Fig. $3 F$ ). The core LV-SRF sequence contained the SRF coding sequence but not its 3'-UTR, thus eliminating the miR-125b binding sites, and the miR-125b mimics could not inhibit SRF expression induced by LV-SRF (Fig. 3F). As shown in Fig. 3G-M, overexpressing SRF by LV-SRF significantly attenuated the antiproliferative and antimigratory effects of miR-125b mimics. The annexin V/PI dual staining assay demonstrated that overexpressed SRF markedly weakened the apoptosis-promoting effect of miR-125b in VSMCs (Fig. 3N-O). Taken together, these data indicate that SRF is a direct target of miR-125b and is involved in miR-125b-induced cellular effects.

Exogenous miR-125b expression regulated SRF expression and suppressed vascular neointimal formation in balloon-injured rat carotid arteries

To explore the effects of miR-125b on VSMC proliferation and neointimal formation in vivo, we used a rat carotid balloon injury model and induced an miR-125b lentiviral vector (LV- miR-125b) to regulate miR-125b expression in the vascular wall. After successful transfection, LV-miR-125b overexpressed miR-125b. The LVs were delivered to the vascular wall after the balloon injury as described. In balloon-injured arteries, neointima formation was found, and the neointima thickness was decreased, as determined by hematoxylin and eosin (H\&E) staining and calculation of the neointimal area (Fig. 5A-B).

After the balloon injury, miR-125b expression in the vascular wall was significantly decreased compared with that in uninjured vascular samples, and LV-miR-125b reoverexpressed miR-125b in the injured vascular walls, as detected by qRT-PCR and FISH (Fig. 5C, 5F-H). Furthermore, LV-miR-125b significantly suppressed neointimal formation 
Fig. 5. Effect of the miR-125b lentivirus on neointimal hyperplasia in a rat carotid artery balloon injury model. (A-B, F) Overexpressing miR-125b by LV-miR-125b inhibited VSMC proliferation and suppressed the neointimal hyperplasia of injured arteries in vivo, as determined by $\mathrm{H} \& \mathrm{E}$ staining and co-FISH-IF. ${ }^{*} \mathrm{p}<0.05$ compared with the LV-control group. (C-D) Overexpressing miR-125b inhibited VSMC proliferation in vivo, as assessed by Western blot and IF. ${ }^{*} \mathrm{p}<0.05$ compared with the uninjured group. (E-F) Transfection of the miR-125b lentivirus remarkably enhanced the miR125b level, as determined by qRT-PCR and FISH. ${ }^{*} \mathrm{p}<0.05,{ }^{* *} \mathrm{p}<0.01$ compared with the uninjured group. (F) A negative relationship was established between the expression of miR-125b and its target gene SRF in rat carotid arteries. Furthermore, miR-125b may exert its suppressive function via regulating SRF in vivo, as shown by the co-FISH-IF assay.

in rat carotid arteries after the balloon injury (Fig. 5G-H). As shown in Fig. 5F-H, the balloon injury significantly increased SRF expression. However, a co-

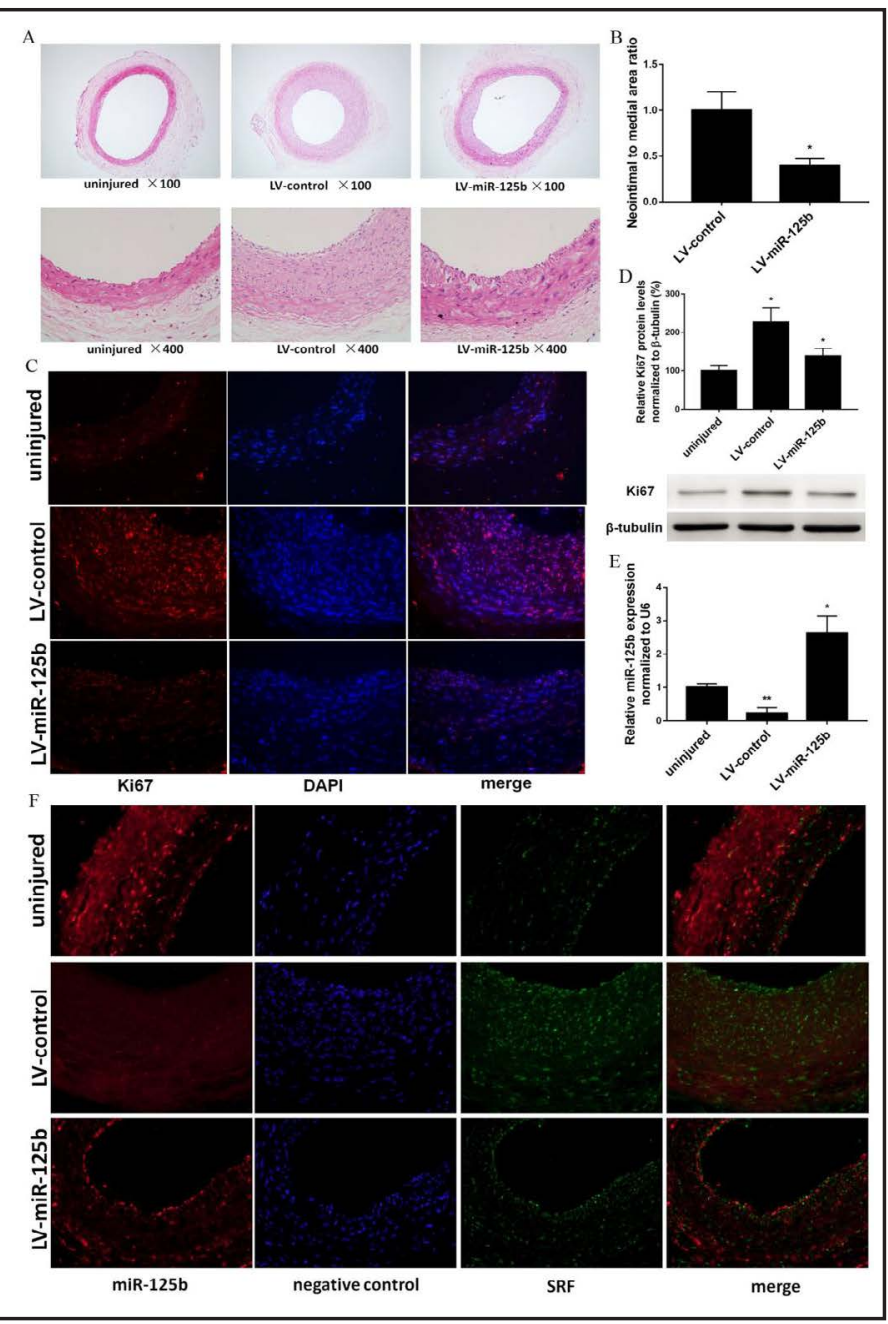
FISH-IF assay demonstrated that after inducing LV-miR-125b, SRF expression decreased as miR-125b expression increased. These results also indicated a negative correlation between SRF and miR-125b expression in vivo.

Furthermore, investigation of the proliferation marker Ki67 revealed that LV-miR$125 \mathrm{~b}$ significantly inhibited VSMC proliferation in vivo, as determined by Western blot and IHC (Fig. 5D-E). All of the present findings revealed that exogenous miR-125b expression suppressed neointimal formation by targeting SRF.

\section{Discussion}

In previous research, we profiled microRNA expression characteristics in normal and ASO human arteries using a microRNA qRT-PCR array [12], revealing miR-125b expression to be significantly down-regulated in the arteries of ASO patients. In this study, we revealed the distribution of miR-125b in human ASO arteries and found that miR-125b exhibited tissue tropism, as it was mainly localized in VSMCs of the artery wall. These characteristics indicate that miR-125b may affect the function of VSMCs in ASO.

The two miR-125b binding sites in the 3'-UTR of SRF mRNA and the negative correlation between miR-125b and SRF in ASO and normal vascular arteries in vivo suggest that SRF may be a miR-125b target. To explore this possibility, we first used a luciferase reporter assay to validate that miR-125b directly binds SRF 3'-UTR regions to regulate SRF expression. Then, 


\section{Cellular Physiology Cell Physiol Biochem 2018;46:1566-1580 \\ and Biochemistry Published online: Apri/ 24, $2018 \quad \begin{aligned} & \text { DOI 1018 2018 The Author(s). Published by S. Karger AG, Basel } \\ & \text { www.karger.com/cpb }\end{aligned}$ \\ Chen et al.: Effects of MiR-125b via SRF on VSMCs}

we confirmed that miR-125b could not inhibit SRF expression induced by LV-SRF, which lacks miR-125b binding sites. Overexpressing SRF by LV-SRF significantly attenuated the antiproliferative and antimigratory effects of miR-125b, suggesting that SRF is a functional downstream target of miR-125b and is involved in the miR-125b-mediated modulation of VSMC function.

SRF is a highly conserved and widely expressed single-copy transcription factor that plays extensive role in circulatory system such as cardiac function and hypertension $[26,27]$. SRF theoretically binds up to 1, 216 permutations of a 10-base pair cis element known as the CArG box [28]. Furthermore, SRF is a transcription factor that binds CArG box elements in promoter regions of target genes that are associated with VSMC differentiation [29-31]. SRF regulates two distinct VSMC gene programs, SMC differentiation genes (SM- $\alpha$-actin, SMMHC), which are linked to muscle differentiation, and growth-related immediate early genes (IEG, Fos/c-fos), which promote cellular growth [29]. SRF must toggle between the VSMC differentiation and growth programs depending on its co-activator and local environmental cues. Myocardin is a muscle-restricted SRF co-activator that forms a ternary complex with SRF to activate VSMC differentiation gene expression [29]. Myocardin greatly increases the association of SRF with SM- $\alpha$-actin and SM-MHC CArG boxes, but not c-fos CArG boxes, to promote transcription [32].

Ligands and receptors of PDGF-BB are up-regulated in both human atherosclerotic plaques $[33,34]$ and in rat and baboon neointimal tissues induced by injury or vascular grafting [35, 36], and PDGF-BB is highly released after vessel injuries, such as ballooninduced femoral artery injuries [37].

PDGF-BB is a well-characterized signaling molecule that induces VSMC phenotypic switching, including profound transcriptional repression of VSMC gene expression, in cultured VSMCs. PDGF-BB treatment decreased myocardin expression and induced decreased SRF binding to SM- $\alpha$-actin and SM-MHC CArG boxes [32].

PDGF-BB is well known as an atherosclerosis promotional factor [38], and it induces the phosphorylation of Elk-1 through MEK1/2 and competes for SRF binding to CArG elements in the promoters of VSMC marker genes [39]. In addition, the phosphorylation of Elk-1 increases SRF binding to the c-fos promoter and transcriptional activation in response to growth factors $[40,41]$. A previous study demonstrated that PTEN might interact with the $\mathrm{N}$-terminal domain of SRF, and PTEN-SRF complex interactions promoted the binding of SRF to essential promoter elements in SMC differentiation genes [42]. PDGF-BB represses SMC differentiation gene transcription at least in part by regulating SRF binding to the CArG boxes of SMC differentiation genes [32]. PDGF-BB stimulation reduced the expression of PTEN, SRF and SM- $\alpha$-actin, which was associated with a loss of PTEN binding and reduced SRF binding to CArG boxes on SMC differentiation gene promoters. However, this phenomenon increased SRF binding to c-Fos CArG boxes, further promoting the proliferation and migration abilities of VSMCs [42].

SRF has also been demonstrated to be essential for maintaining the homeostasis of VMSC actin cytoskeleton, which is associated with cell migration [43]. Numerous actin cytoskeleton genes are direct targets of SRF, and activated genes encoding the cytoskeletal apparatus indirectly stimulate SRF activity. The positive feedback mechanism of the SRF/ actin cytoskeleton loop is vital for cytoskeletal homeostasis and cell migration ability [31].

Taken together, PDGF-BB together with SRF might promote the migration of VSMCs from the vessel media to the intima, thus promoting excessive proliferation under certain circumstances, and SRF acts as a key factor in this scenario. However, miR-125b degraded SRF mRNA and negatively regulated SRF expression at the post-transcriptional level to regulate this important biological process.

In the absence of the SRF 3'-UTR, SRF up-regulation via the administration of SRF lentivirus markedly promoted the proliferation and migration abilities of VSMCs even when miR-125b mimics were added simultaneously. In the IHC assay, increased levels of SRF were accompanied by neointimal formation, indicating that SRF has proproliferation and promigration effects on VSMCs under this condition.

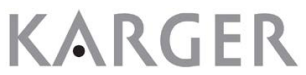


In the carotid artery balloon injury model, overexpressing miR-125b in the rat arteries led to the down-regulation of SRF and the inhibition of VSMC proliferation and neointimal formation. These results further confirmed SRF as a miR-125b target in vivo and indicated that exogenous miR-125b expression may be used to inhibit the progression of ASO and vascular restenosis.

\section{Conclusion}

In summary, the present study revealed that down-regulated miR-125b expression is a novel regulator of vascular neointimal growth and function due to the regulation of VSMC proliferation and migration via directly targeting SRF, and exogenous miR-125b may inhibit VSMC proliferation and migration. These findings offer new insights that may be useful in the treatment of arteriosclerosis, vascular restenosis, and other proliferative vascular diseases.

\section{Acknowledgements}

This research was supported by the China National Natural Scientific Fund (Grant No. 81570434, 81170293, 81670441).

\section{Disclosure Statement}

The authors have no conflicts of interest to declare.

\section{References}

$>1$ Diehm C, Allenberg JR, Pittrow D, Mahn M, Tepohl G, Haberl RL, Darius H, Burghaus I, Trampisch HJ:

Mortality and vascular morbidity in older adults with asymptomatic versus symptomatic peripheral artery disease. Circulation 2009;120:2053-2061.

2 McDermott MM: Medications for improving walking performance in peripheral artery disease: still miles to go. JAMA 2013;309:487-488.

3 Malgor RD, Alahdab F, Alalahdab F, Elraiyah TA, Rizvi AZ, Lane MA, Prokop LJ, Phung OJ, Farah W, Montori VM, Conte MS, Murad MH: A systematic review of treatment of intermittent claudication in the lower extremities. J Vasc Surg 2015;61:54S-73S.

-4 Reinecke H, Unrath M, Freisinger E, Bunzemeier H, Meyborg M, Lüders F, Gebauer K, Roeder N, Berger K, Malyar NM: Peripheral arterial disease and critical limb ischaemia: still poor outcomes and lack of guideline adherence. Eur Heart J 2015;36:932-938.

5 Yahagi K, Otsuka F, Sakakura K, Sanchez OD, Kutys R, Ladich E, Kolodgie FD, Virmani R, Joner M: Pathophysiology of superficial femoral artery in-stent restenosis. J Cardiovasc Surg (Torino) 2014;55:307323.

-6 Farh KK, Grimson A, Jan C, Lewis BP, Johnston WK, Lim LP, Burge CB, Bartel DP: The widespread impact of mammalian MicroRNAs on mRNA repression and evolution. Science 2005;310:1817-1821.

7 Bartel DP: MicroRNAs: target recognition and regulatory functions. Cell 2009;136:215-233.

-8 Yang JS, Phillips MD, Betel D, Mu P, Ventura A, Siepel AC, Chen KC, Lai EC: Widespread regulatory activity of vertebrate microRNA* species. RNA 2011;17:312-326.

-9 Siasos G, Kollia C, Tsigkou V, Basdra EK, Lymperi M, Oikonomou E, Kokkou E, Korompelis P, Papavassiliou AG: MicroRNAs: Novel diagnostic and prognostic biomarkers in atherosclerosis. Curr Top Med Chem 2013;13:1503-1517.

10 Imanishi T, Akasaka T: MicroRNAs in peripheral artery disease. Curr Top Med Chem 2013;13:1589-1595.

11 Madrigal-Matute J, Rotllan N, Aranda JF, Fernández-Hernando C: MicroRNAs and atherosclerosis. Curr Atheroscler Rep 2013;15:322. 


\section{Cellular Physiology Cell Physiol Biochem 2018;46:1566-1580 \begin{tabular}{l|l} 
DOI: 10.1159/000489203 & $\begin{array}{l}\text { O 2018 The Author(s). Published by S. Karger AG, Basel } \\
\text { www.karger.com/cpb }\end{array}$ \\
\hline
\end{tabular} \\ Chen et al.: Effects of MiR-125b via SRF on VSMCs}

12 Wang M, Li W, Chang GQ, Ye CS, Ou JS, Li XX, Liu Y, Cheang TY, Huang XL, Wang SM: MicroRNA-21 regulates vascular smooth muscle cell function via targeting tropomyosin 1 in arteriosclerosis obliterans of lower extremities. Arterioscler Thromb Vasc Biol 2011;31:2044-2053.

13 Boucher JM, Peterson SM, Urs S, Zhang CX, Liaw L: The miR-143/145 cluster is a novel transcriptional target of Jagged-1/Notch signaling in vascular smooth muscle cells. J Biol Chem 2011;286:28312-28321.

14 Liu X, Cheng YH, Yang J, Xu L, Zhang CX: Cell-specific effects of miR-221/222 in vessels: molecular mechanism and therapeutic application. J Mol Cell Cardiol 2012;52:245-255.

-15 Hu W, Wang M, Yin HH, Yao C, He Q, Yin LP, Zhang CX, Li W, Chang GQ, Wang SM: MicroRNA-1298 is regulated by DNA methylation and affects vascular smooth muscle cell function by targeting connexin 43 Cardiovasc Res 2015;107:534-545.

16 Shan Z, Yao C, Li ZL, Teng Y, Li W, Wang JS, Ye CS, Chang GQ, Huang XL Li XX, Wang WJ, Wang SM: Differentially expressed microRNAs at different stages of atherosclerosis in ApoE-deficient mice. Chin Med J (Engl) 2013;126:515-520.

-17 Li YX, Ouyang M, Shan Z, Ma JY, Li J, Yao C, Zhu ZR, Zhang LJ, Chen LZ, Chang GQ, Wang SM, Wang WJ: Involvement of MicroRNA-133a in the Development of Arteriosclerosis Obliterans of the Lower Extremities via RhoA Targeting. J Atheroscler Thromb 2015;22:424-432.

18 Liang L, Wong CM, Ying Q, Fan DN, Huang S, Ding J, Yao J, Yan M, Li J, Yao M, Ng IO, He X: MicroRNA-125b suppressesed human liver cancer cell proliferation and metastasis by directly targeting oncogene LIN28B2. Hepatology 2010;52:1731-1740.

19 Rajabi H, Jin C, Ahmad R, McClary C, Joshi MD, Kufe D: MUCIN 1 ONCOPROTEIN EXPRESSION IS SUPPRESSED BY THE miR-125b ONCOMIR. Genes Cancer 2010;1:62-68.

20 Guan Y, Yao H, Zheng Z, Qiu G, Sun K: MiR-125b targets BCL3 and suppresses ovarian cancer proliferation. Int J Cancer 2011;128:2274-2283.

-21 Huang L, Luo J, Cai Q, Pan Q, Zeng H, Guo Z, Dong W, Huang J, Lin T: MicroRNA-125b suppresses the development of bladder cancer by targeting E2F3 Int J Cancer 2011;128:1758-1769.

-22 Chapiro E, Russell LJ, Struski S, Cavé H, Radford-Weiss I, Valle VD, Lachenaud J, Brousset P, Bernard OA, Harrison CJ, Nguyen-Khac F: A new recurrent translocation t(11;14)(q24;q32) involving IGH@ and miR125b-1 in B-cell progenitor acute lymphoblastic leukemia. Leukemia 2010;24:1362-1364.

23 Hirsch HA, Iliopoulos D, Joshi A, Zhang Y, Jaeger SA, Bulyk M, Tsichlis PN, Shirley LX, Struhl K: A transcriptional signature and common gene networks link cancer with lipid metabolism and diverse human diseases. Cancer Cell 2010;17:348-361.

-24 Cheng Y, Liu X, Yang J, Lin Y, Xu DZ, Lu Q, Deitch EA, Huo Y, Delphin ES, Zhang C: MicroRNA-145, a novel smooth muscle cell phenotypic marker and modulator, controls vascular neointimal lesion formation. Circ Res 2009;105:158-166.

-25 Kim J, Zhang L, Peppel K, Wu JH, Zidar DA, Brian L, DeWire SM, Exum ST, Lefkowitz RJ, Freedman NJ: $\beta$-arrestins regulate atherosclerosis and neointimal hyperplasia by controlling smooth muscle cell proliferation and migration. Circ Res 2008;103:70-79.

-26 Lutze P, Wanka H, Bäumgen I, Staar D, Grunow B, Peters J: An Alternative Promoter in Intron1 of the Renin Gene is Regulated by Glucose Starvation via Serum Response Factor. Cell Physiol Biochem 2017;42:14471457.

27 Zhou N, Lee JJ, Stoll S, Ma B, Costa KD, Qiu H: Rho Kinase Regulates Aortic Vascular Smooth Muscle Cell Stiffness Via Actin/SRF/Myocardin in Hypertension. Cell Physiol Biochem 2017;44:701-715.

28 Hendrix JA, Wamhoff BR, McDonald OG, Sinha S, Yoshida T, Owens GK: 5' CArG degeneracy in smooth muscle alpha-actin is required for injury-induced gene suppression in vivo. J Clin Invest 2005;115:418-427.

29 Miano JM: Serum response factor: toggling between disparate programs of gene expression. J Mol Cell Cardiol 2003;35:577-593.

30 Miano JM: Role of serum response factor in the pathogenesis of disease. Lab Invest 2010;90:1274-1284.

-31 Sun Q, Chen G, Streb JW, Long X, Yang Y, Stoeckert CJ, Miano JM: Defining the mammalian CArGome. Genome Res 2006;16:197-207.

-32 McDonald OG, Wamhoff BR, Hoofnagle MH, Owens GK: Control of SRF binding to CArG box chromatin regulates smooth muscle gene expression in vivo. J Clin Invest 2006;116:36-48.

-33 Abedi H, Zachary I: Signalling mechanisms in the regulation of vascular cell migration. Cardiovasc Res 1995;30:544-556. 


\section{Cellular Physiology Cell Physiol Biochem 2018;46:1566-1580

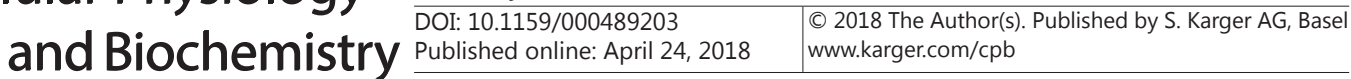 \\ Chen et al.: Effects of MiR-125b via SRF on VSMCs}

-34 Wilcox JN, Smith KM, Williams LT, Schwartz SM, Gordon D: Platelet-derived growth factor mRNA detection in human atherosclerotic plaques by in situ hybridization. J Clin Invest 1988;82:1134-1143.

-35 Majack RA, Majesky MW, Goodman LV: Role of PDGF-A expression in the control of vascular smooth muscle cell growth by transforming growth factor-beta. J Cell Biol 1990;111:239-247.

-36 Golden MA, Au YP, Kirkman TR, Wilcox JN, Raines EW, Ross R, Clowes AW: Platelet-derived growth factor activity and mRNA expression in healing vascular grafts in baboons. Association in vivo of platelet-derived growth factor mRNA and protein with cellular proliferation. J Clin Invest 1991;87:406-414.

-37 Uchida K, Sasahara M, Morigami N, Hazama F, Kinoshita M: Expression of platelet-derived growth factor B-chain in neointimal smooth muscle cells of balloon injured rabbit femoral arteries. Atherosclerosis 1996;124:9-23.

38 Bennett MR, Sinha S, Owens GK: Vascular Smooth Muscle Cells in Atherosclerosis. Circ Res 2016;118:692702.

-39 Wang Z, Wang DZ, Hockemeyer D, McAnally J, Nordheim A, Olson EN: Myocardin and ternary complex factors compete for SRF to control smooth muscle gene expression. Nature 2004;428:185-189.

40 Zhong TP, Rosenberg M, Mohideen MA, Weinstein B, Fishman MC: gridlock, an HLH gene required for assembly of the aorta in zebrafish. Science 2000;287:1820-1824.

41 Zhou J, Hu G, Herring BP: Smooth muscle-specific genes are differentially sensitive to inhibition by Elk-1 Mol Cell Biol 2005;25:9874-9885.

42 Horita H, Wysoczynski CL, Walker LA, Moulton KS, Li M, Ostriker A, Tucker R, McKinsey TA, Churchill ME, Nemenoff RA, Weiser-Evans MC: Nuclear PTEN functions as an essential regulator of SRF-dependent transcription to control smooth muscle differentiation. Nat Commun 2016;7:1-17.

43 Miano JM, Long X, Fujiwara K: Serum response factor: master regulator of the actin cytoskeleton and contractile apparatus. Am J Physiol Cell Physiol 2007;292:C70-81. 